may be used in hydrocarbon exploration. This begins with a review of surface manifestations of oil, both the visible seeps of oil and gas onshore and offshore, and surface geochemical prospecting. A chapter on subsurface prospecting follows, describing the analysis and interpretation of cuttings gas as well as ways in which source rocks may be studied to determine their oil or gas potential, and their degree of maturity.

The next chapter shows how crude oils may be correlated with their source beds, and the text concludes with a short account of geochemical prospect evaluation. Finally, there is a glossary, forty pages of references and author and subject indexes.

Inevitably, this book invites comparison with Tissot and Welte's recent book, Petroleum Formation and Occurrence (Springer: Berlin, Heidelberg and New York, 1978), on the same topic. They both cover the same subject matter and both draw freely (and with due acknowledgement) on each other's work. Both books are excellent and the only simple comparison that may be drawn is that Hunt's book perhaps emphasises geology more than chemistry, while for Tissot and Welte's book the converse is true. Certainly, this reviewer, who is only a geologist, finds Hunt's book the easier to read.

The arrangement of the vast amount of material in a book of this kind presents many problems but could perhaps have been improved. For example, discussion of source rocks should perhaps precede an account of the emigration of hydrocarbons from them. Sections dealing with palaeotemperature analysis could perhaps have been grouped together, and their relative merits and limitations contrasted, instead of their being distributed through several chapters of the book. Since oil and gas formation is so intimately related it seems an unnecessary distinction to discuss their genesis in separate chapters.

To counteract these comments, however, it must be stated that the book is well written, well researched and pleasantly produced. All the line illustrations have been specially prepared for this work and each part begins with a half-tone plate. $\mathbf{A}$ particularly helpful feature is the inclusion of a summary and list of supplementary reading at the end of each chapter.

The wide range of case histories discussed is impressive. It is unusual to find a geologist of the USA who is familiar with, or at least prepared to quote, data from outside North America. This reviewer could spot only two important omissions. There was no reference to Porfir'ev's paper on the inorganic origin of oil (Bull.Am. Ass. Petrol. Geol. 58, 3-33, 1974). This is probably the most accessible exposition of the Russian igneous oil theory for readers in the free world. Several papers related to the correlation of vitrinite reflectivity and electron spin resonance are also omitted.

These are, however, minor blemishes on a major textbook. No petroleum geologist should be without a copy of Petroleum Geochemistry and Geology.

R.C. Selley is Reader in Petroleum Geology at Imperial College, University of London, UK.

\section{Plankton research}

\section{C.M. Yonge}

Zoogeography and Diversity in Plankton. Edited by S. van der Spoel and A.C. Pierrot-Bults. Pp.410. (Edward Arnold: Maidenhead, 1979.) £37.50.

THIS most attractive book is a revelation of the extent and cohesion of plankton research. It appears at about the centenary of the initial work by Hensen which led, at the beginning of the century, to the formulation by the International Council for the Exploration of the Sea of a programme involving the quantitative study of plankton in relation to hydrography on the one hand and fisheries on the other. These first collections and counting of plankton have gradually spread over the face of globe, with whaling investigations in the Southern Ocean and the International Indian Ocean Expedition extending knowledge into these previously little known areas.

Problems of distribution and of speciation, the dominant themes in this book, are vast and perplexing. In contrast to the terrestrial habitat, that of marine plankton is three-dimensional and continuous. There are notable distinctions between neritic (coastal) and oceanic populations, with latitudinal divisions largely temperature based and different biotopes in depth represented by epipelagic, mesopelagic and bathypelagic plankton. Distinctions between habitats are often best defined by the resident 'indicator' species, most frequently chaetognaths. The Challenger studies of Murray and Renard on the deposition of planktonic skeletons on the ocean floor are the basis of modern work on the history of ocean basins and provide important evidence concerning continental drift.

An adequately authoritative survey of this immense field demands specialist treatment and most exacting editorial standards. Both are supplied by the contributions of fourteen authors from seven countries, most competently organised by S. van der Spoel and A.C. Pierrot-Bults of the Institute of Taxonomic Zoology, University of Amsterdam. Clearly drawn figures and an extensive literature list complete the attractions of a book which presents information essential to all interested in the full extent of biological enquiry. It makes immediate appeal to the scientific imagination.

Sir Maurice Yonge is Honorary Fellow in Zoology at the University of Edinburgh, UK.

\section{Light physics}

\section{P. W. Hawkes}

Optoelectronic Devices and Optical Imaging Techniques. By D. A. Ross. Pp. 137. (Macmillan: London, 1979.) Hardback £12; paperback $£ 4.95$.

THIS clear, simple introduction to a range of devices that convert electrical energy into light or generate such energy from light will appeal to a wide student audience, particularly to those who need to acquire only a smattering of the physics involved before exploring the many applications. The text is orientated towards specific devices, chapters being devoted to LEDs, photoconductors, photodiodes and phototransistors, solar cells and laser diodes; two other chapters are concerned with noise in such devices and in optical recording media, first film and then CCDs. All these are described in easy, uncomplicated language and illustrated with uncluttered line diagrams and a photograph showing CCD-aided decapitation of carrots! I was a little startled to encounter, for the first time for many years, the jovial, avuncular style of older school textbooks; a line diagram is described as "An artist's impression of a photon", we are told that "It would be a minor disaster to be forced to abandon Fourier analysis . . .", but isolated examples cannot properly convey the flavour which nonetheless pervades the book.

The publishers have sensibly also brought out the book in paperback. Libraries will of course be more interested in the cased edition, but the paperback version is good value at $£ 4.95$; it should sell well, not only to students but to others, since plenty of people are interested in understanding these devices by which they are surrounded.

P.W. Hawkes is Maître de Recherches in the Laboratoire d'Optique Electronique du CNRS, Toulouse, France. 